\title{
Circulation of the Caribbean Sea ${ }^{1}$
}

\author{
ArNold L. Gordon \\ Lamont Geological Observatory of Columbia University \\ Palisades, New York 10964
}

\begin{abstract}
The geostrophic method was applied to six north-south hydrographic profiles across the Caribbean Sea and one across the Yucatan Strait. An axis of flow exists in the southern third of the Caribbean Sea. It flows directly over the steep slope in the reference layer found by Defant's method. This condition is similar to that of the Gulf Stream. The baroclinic mass distribution extends to approximately 1200 meters. Below this, the flow is weak $(<5 \mathrm{~cm} / \mathrm{sec}$ except in the depths of the Cayman and Yucatan basins, where currents of over $10 \mathrm{~cm} / \mathrm{sec}$ occur. The deep and bottom flow may fluctuate in phase with overflow through the Windward and Anegada passageways. The main axis of flow corresponds closely with the main axis of spreading found by the core method in both the salinity maximum and the salinity minimum layers. The volume transport across the meridional section in the Caribbean is about $31 \times 10^{3} \mathrm{~m}^{3} / \mathrm{sec}$ toward the west. The northern passageways contribute only a small part of this water. The major outlet is the Yucatan Strait, where the calculated geostrophic volume transport corresponds to the transport through the Straits of Florida. The surface flow is directly affected by the wind. The upper baroclinic field of mass is produced by the Ekman transport of the light surface water toward the northern boundary. It is expected that divergences occur to the south of the main flow, and convergences occur to the north. This is supported by salinity and temperature sections. The upwelling in the south is calculated to be of the order of $10^{-4} \mathrm{~cm} / \mathrm{sec}$ at the bottom of the Ekman layer.
\end{abstract}

\section{INTRODUCTION}

The descriptive oceanography of the Caribbean Sea has been extensively studied by Parr [1937], Dietrich [1939], and Wüst [1963, 1964]; however, little has been done about studying the dynamics of the circulation. As shown by past investigators, the Caribbean Sea water structure is highly stratified in the upper 1200 meters, with weak stratification between 1200 and 2000 meters and nearly homogeneous conditions below 2000 meters. This water structure is directly related to the sill depths of the Antillean island arch. The passages in the Lesser Antilles, through which most of the Caribbean Sea water enters, have an effective sill depth of slightly less than 1200 meters. The passages in the Greater Antilles, excluding the Yucatan Strait, are less than 2000 meters deep. It is through these passages (Windward and Anegada passages) that the deep and bottom water within the Caribbean Sea is renewed.

The homogeneous deep water has a mean potential temperature of $3.80^{\circ} \mathrm{C}$ and a salinity

${ }^{1}$ Lamont Geological Observatory Contribution 1120. of $34.98 \%$ [Sturges, 1965]. The exact nature of the renewal is in dispute. Dietrich [1939] suggested a steady cascading of North Atlantic Deep Water into the Caribbean. Wüst [1964] indicated a fluctuating overflow with a period of major renewal during the 1930's and during 1960 and minor overflow during other periods. Worthington [1955, 1966] believes that no renewal has occurred in recent times and suggests a slow warming of bottom water within the Caribbean Sea. The numerous passages of the Lesser Antilles permit free access of highly saline Subtropical Underwater (100-200 meters) and less saline Sub-Antarctic Intermediate Water (600-800 meters) into the Caribbean Sea, the source regions lying to the northeast and south, respectively, of the Caribbean. Using the core method, Wüst has investigated the spreading of these water masses. The main axis of this spreading is in the southern Caribbean Sea approximately $200-300 \mathrm{~km}$ north of South America in the vicinity of the Caribbean Current. (See Figure 10.) This current is an extension of the Guiana Current. It eventually flows through the Yucatan and Florida straits, contributing to the volume transport of the 
Gulf Stream. The reader is referred to Wüst's [1964] text and atlas for details of the water structure in the Caribbean Sea.

The purpose of this paper is to present the geostrophic velocities and transports and relate them to the earlier descriptive results. In addition, a wind-driven model that may account for the observed field of mass of the Caribbean Sea is proposed.

\section{Geostrophic Catculations}

The velocity field necessary to balance the horizontal pressure gradient, assuming total balance by the Coriolis terms of the equation of motion, is found by applying the geostrophic relation. This method is based on the Bjerknes circulation theorem. The theorem was modified for oceanographic conditions by Sandström and Helland-Hansen [1903]. The accuracy of this method was demonstrated by Wüst [1924] in his calculations of currents in the Florida Straits and their comparison with direct measurements.

The hydrographic data from the Atlantis and
Crawford were found to be of sufficiently high quality for geostrophic calculations. In addition, many of these stations form oceanographic profiles oriented at right angles to the expected flow with a spacing of $4^{\circ}-5^{\circ}$ of longitude. Figure 1 shows the stations used in this study and the profiles for which geostrophic calculations were performed. From these stations, the depth of the zero reference layer was calculated by Defant's method [Defant, 1941, 1961]. Figure 2 is a map of the topography of this layer in the Caribbean Sea. It is the layer of approximately zero zonal velocity. Since meridional flow in the Caribbean is small, as indicated by Wüst's core maps, this zero reference layer can be considered to be valid for all directions. The isobaths in the vicinity of the eastern Caribbean Sea are compatible with the reference layer for the Atlantic Ocean prepared by Defant [1941].

The main features of the zero layer are: (1) a steep slope along the southern boundary of the Caribbean Sea directly below the main axis of the Caribbean Current (similar to the steep

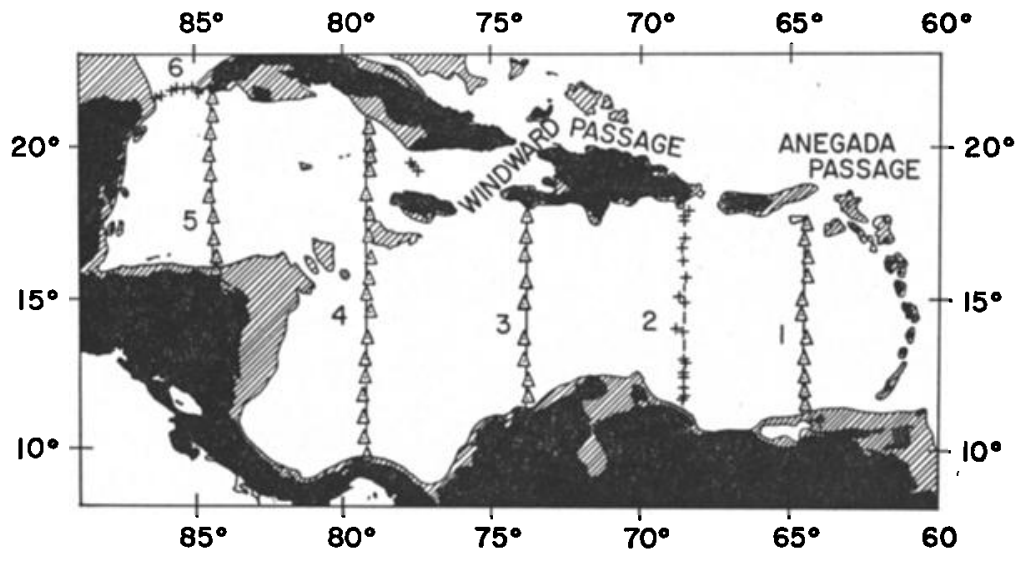

\begin{tabular}{clll}
\hline Profile & \multicolumn{1}{c}{ Ship } & \multicolumn{1}{c}{ Station Numbers } & \multicolumn{1}{c}{ Date } \\
\hline 1 & Crawoford & $333-342 ; 345$ & February 1958 \\
2 & Atlantis & $1505-1507 ; 1509-1512 ; 1514-1515$ & March 1933 \\
$2^{\prime}$ & Atlantis & $5233-5235 ; 5257-5262$ & Nov.-Dec. 1954 \\
3 & Crawford & $355-358 ; 360-364$ & Feb.-March 1958 \\
4 & Crawford & $382-399$ & March 1958 \\
5 & Crawford & $370-379$ & March 1958 \\
6 & Atlantis & $1604-1610$ & May 1933 \\
Other & Atlantis & $1570-1572$ & April 1933 \\
\hline
\end{tabular}

Fig. 1. Hydrographic stations used in geostrophic calculations. Triangles, Crawford; plus signs, Atlantis. 


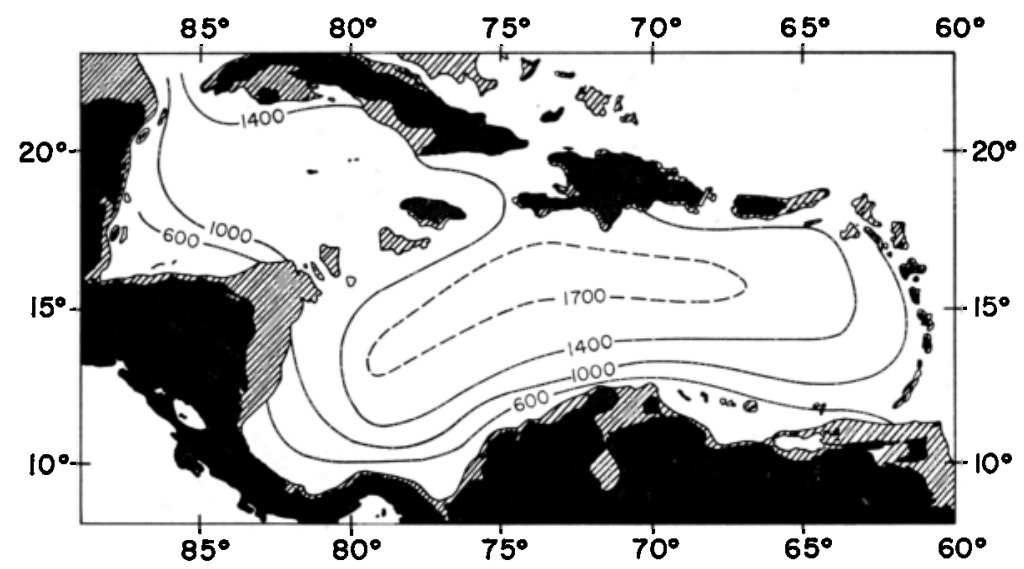

Fig. 2. Zero reference layer found by Defant's method (depths in meters).

slope of the zero reference layer below the Gulf Stream) and (2) a depression in the topography of the zero layer in the central regions of the Venezuela and Colombia basins. The total relief of the layer is 1100 meters. The zero reference layer occurs between 800 and 1000 meters near the Lesser Antilles, indicating the possibility of flow into the Atlantic Ocean at the bottom of the deeper passageways.

The geostrophic velocities are only a component of the total flow. With the exception of boundary layers, however, this component accounts for most of the water velocity. By means of a Gaussian error distribution for the anomaly of specific volume error, it can be shown that the $90 \%$ confidence level of the calculated geostrophic velocity in the Caribbean Sea is usually less than $5 \mathrm{~cm} / \mathrm{sec}$. This value was found using a $0.02{ }^{\circ} \mathrm{C}$ temperature error and a salinity $0.005 \%$ error, and a station spacing of $60 \mathrm{~km}$. The precision decreases with increasing distance from the reference layer. Table 1 shows the velocity $90 \%$ confidence layer, for a zero reference layer at 800,1200 , and 1600 meters, at the indicated standard levels for an $f L$ value of 230 at a latitude of $15^{\circ}$. This term is in the denominator of the Helland-Hansen geostrophic relation, where $f$ is the Coriolis parameter $2 \omega$ sin (lat) and $L$ is the distance between stations. The percentage of error would decrease as the baroclinicity of the water structure increases, since the error remains constant while the geostrophic velocity increases. For a discussion of the accuracy of the geostrophic approximation see Seiwell [1939], Reid [1959], Fomin [1964], and Gordon [1965]. The Gaussian error treatment from which Table 1 is derived is discussed in detail by Gordon [1965].

The geostrophic velocities are represented in Figures 3 and 4 in box form, since the values represent an average velocity at each level between adjacent hydrographic stations. For areas near the coast, where the zero reference layer would be below the sea floor, an approximate velocity is determined by the extrapolative method [Fomin, 1964]. Two profiles were con-

TABLE 1. $90 \%$ Confidence Level of Geostrophic Velocities at Standard Depths for Three Reference Levels

90\% Confidence $(\mathrm{cm} / \mathrm{sec}) f L=230$.

\begin{tabular}{rrrr}
\hline & \multicolumn{3}{l}{ Reference Level, meters } \\
\cline { 2 - 4 } $\begin{array}{c}\text { Standard } \\
\text { Level }\end{array}$ & 800 & 1200 & 1600 \\
& & & \\
\hline 100 & 1.4 & 1.9 & 2.4 \\
200 & 1.3 & 1.9 & 2.3 \\
300 & 1.2 & 1.8 & 2.3 \\
400 & 1.1 & 1.7 & 2.2 \\
600 & 1.0 & 1.7 & 2.2 \\
800 & 0.7 & 1.5 & 2.0 \\
1000 & 0.0 & 1.3 & 1.8 \\
1200 & 0.8 & 0.8 & 1.6 \\
1400 & 1.3 & 0.0 & 1.3 \\
1600 & 1.6 & 0.8 & 0.8 \\
2000 & 1.8 & 1.3 & 0.0 \\
2500 & 2.3 & 1.8 & 1.3 \\
3000 & 3.1 & 2.9 & 2.5 \\
3500 & 4.0 & 3.8 & 3.5 \\
4000 & 4.7 & 4.5 & 4.2 \\
& 5.2 & 5.1 & 4.9 \\
\hline
\end{tabular}




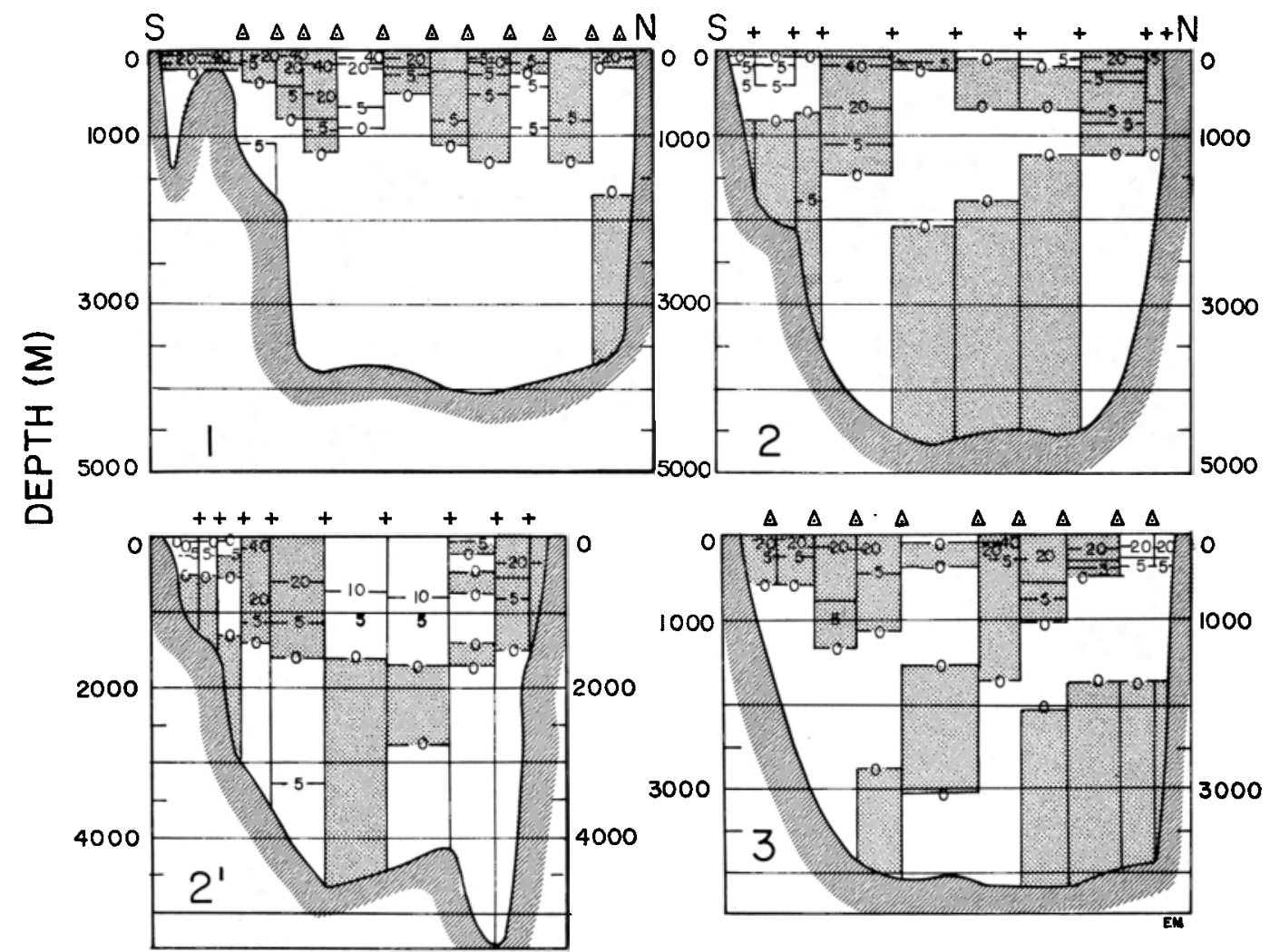

Fig. 3. Geostrophic velocities for profiles $1,2,2$, and 3. Shaded areas indicate westward flowing current (values in centimeters per second).

structed for the longitude $68^{\circ} 30^{\prime}$ : profile 2 is from March 1933 Atlantis data and profile $Z^{\prime}$ is from November-December 1954 Atlantis data.

\section{Geostrophic Velocitims}

Profiles 1, 2, $2^{\prime}$ and 3 are similar in the following respects: (1) moderate mostly westerly currents in the upper 1200 meters, (2) a current maximum (the Caribbean Current) within 500 $\mathrm{km}$ north of the South American coast, (3) a secondary maximum in westward flow about 100 $\mathrm{km}$ farther north, and (4) sluggish deep flow (below or nearly at the $90 \%$ confidence limit). Profiles 2 and $2^{\prime}$ are in good agreement, indicating the steady-state condition of the circulation pattern. These sections agree even in secondary characteristics, as in the subsurface east current between 100 and 150 meters at the southern boundary. The deep flow is slightly more active in the 1933 section, which is consistent with Wüst's conclusion on the basis of oxygen concentration of greater renewal of the deep water during the 1930's.

At the Hispaniola coast on profile 3 there is a strong easterly current at the surface. This counter flow is associated with the hydrodynamical effect of the peninsula on the southern coast of Hispaniola. The eastward components in other parts of profile 3 and in profiles 1 and 2 are, for the most part, minor. The large east current immediately to the north of the axis of flow in profile 1 is not supported by surface current data or by the results of Wüst's core study. Its cause is not known, though a large internal wave at the time of station 339 or 340 may be responsible. The true nature of this feature cannot be known until extensive direct current measurements are made.

Profile 4 along $79^{\circ} 40 \mathrm{~W}$ is the longest and the most complicated section. The main axis of the Caribbean Current is not as well defined as it is in the profiles 1 to 3 . From the core maps, 
Wüst concluded a curved axis of spreading that crosses the $79^{\circ} 40^{\circ} \mathrm{W}$ meridian numerous times. It is expected that the axis of flow behaves similarly.

The deep current in the Cayman basin found in the 1958 sections (4 and 5) is weak. A secondary profile across this basin, consisting of three 1933 Atlantis stations (stations 1570 to 1572), shows a deep westward current, with a magnitude of $20 \mathrm{~cm} / \mathrm{sec}$ at 3000 meters. Since the overflow through the Windward Passage would be channeled by the Cayman basin, the data suggest that there was more overflow when the 1933 stations were taken than there was during the 1958 period. There are no deep data suitable for geostrophic calculations in the Cayman basin to determine the bottom currents. From the bottom potential temperature map of Wüst, a moderate westward current is expected.

The axis of flow is fairly broad across profile 5 . The deep flow is slightly more active than in the profiles to the east, with values of $13 \mathrm{~cm} /$ sec found between stations 371 and 372 . No station pairs penetrate the deep Cayman basin; therefore, deep currents cannot be calculated. A moderate countercurrent is found along the coast of Cuba. After crossing this meridian, the Caribbean Current turns northward and accelerates to a velocity greater than four knots on passing through the Yucatan Strait. The area of this intensification should be subjected to a complete hydrographic investigation. It is possible that the flow in this region is not in geostrophic equilibrium.

The maximum velocities in the Yucatan Strait (profile 6) are on the western side of the strait with a southerly current at the eastern end. In 1887 Pillsbury measured the currents at five levels down to 235 meters. Both Pillsbury's [1887] data and the hydrographic data used in profile 6 represent conditions in the spring. Figure 5 is constructed from Pillsbury's measurements. There is good agreement with the geostrophic results. Both show a maximum northward flow in the western side of the strait and a southward flowing current near Cuba. Both show a secondary maximum to the east of the main axis of flow. The zone of anticyclonic shear
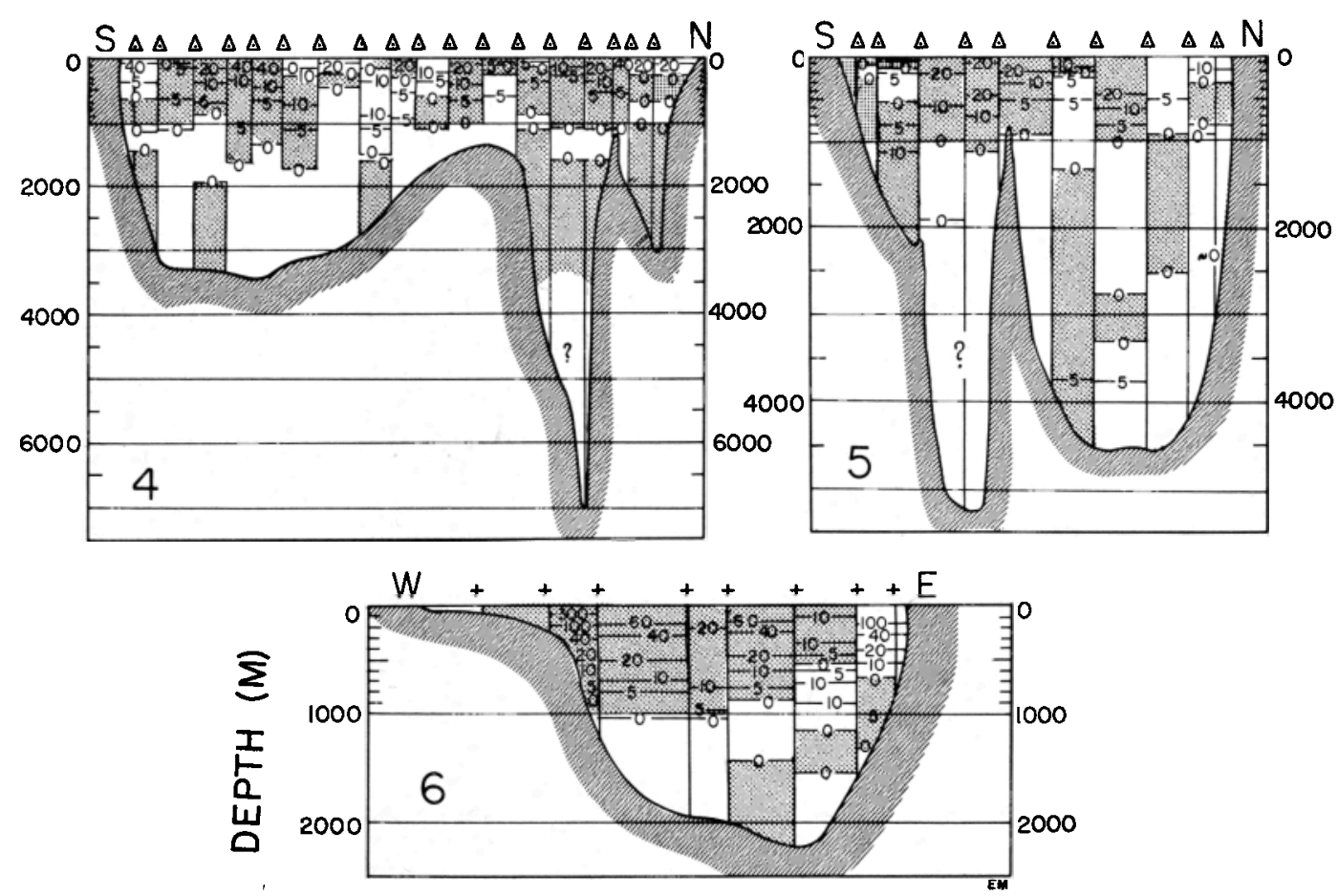

Fig. 4. Geostrophic velocities for profiles 4, 5, and 6. Shaded areas indicate westward flowing current (values in centimeters per second). 


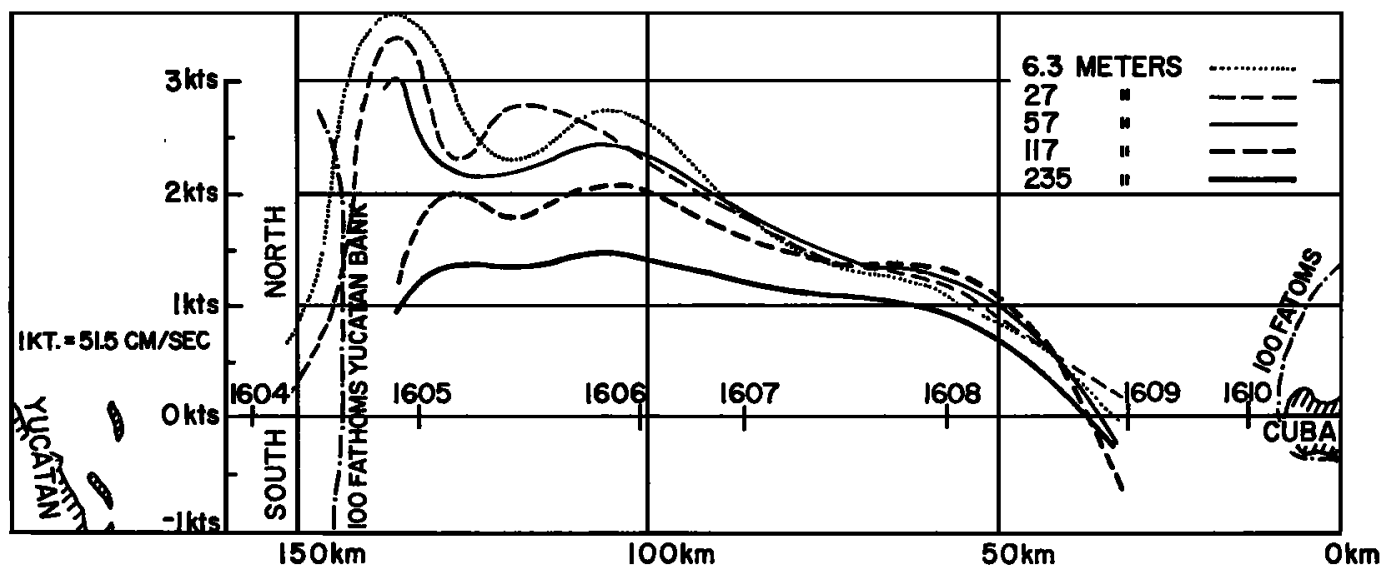

Fig. 5. Direct current measurements of Pillsbury [1887] across the Yucatan Strait. The Atlantis stations 1604-1610 used in profile 6 are plotted on the zero velocity base line.

between the two maxima was also found by the G.E.K. measurements of Cochrane [1964]. The velocity gradient across the strait found by Pillsbury in 1887 and the velocity gradient from the Atlantis 1933 section are basically very similar:

The axes of spreading for the Subtropical Underwater and Sub-Antarctic Intermediate Water [Wüst, 1963, 1964] and the axis of flow (maximum current) would coincide at all points if both were introduced into the Caribbean through the same passage. When the source is different, the two axes would, as a result of lateral diffusion, approach each other and finally merge to the west of the Lesser Antilles. Figure 6 compares the axis of spreading and the velocities in the Subtropical Underwater. The velocities in the axis of flow are between 40 and 50 $\mathrm{cm} / \mathrm{sec}$ in the eastern Caribbean, reducing to less than $30 \mathrm{~cm} / \mathrm{sec}$ in the central regions. The velocities increase in the western Caribbean. The axis of spreading follows the axis of flow. with the exception of the crossing at profile 1 . This is the result of the source of the Subtropical Underwater (north of St. Vincent Island) being more northerly than the main entrance point of the Caribbean Current (between Grenada and South America). The Subtropical Underwater is

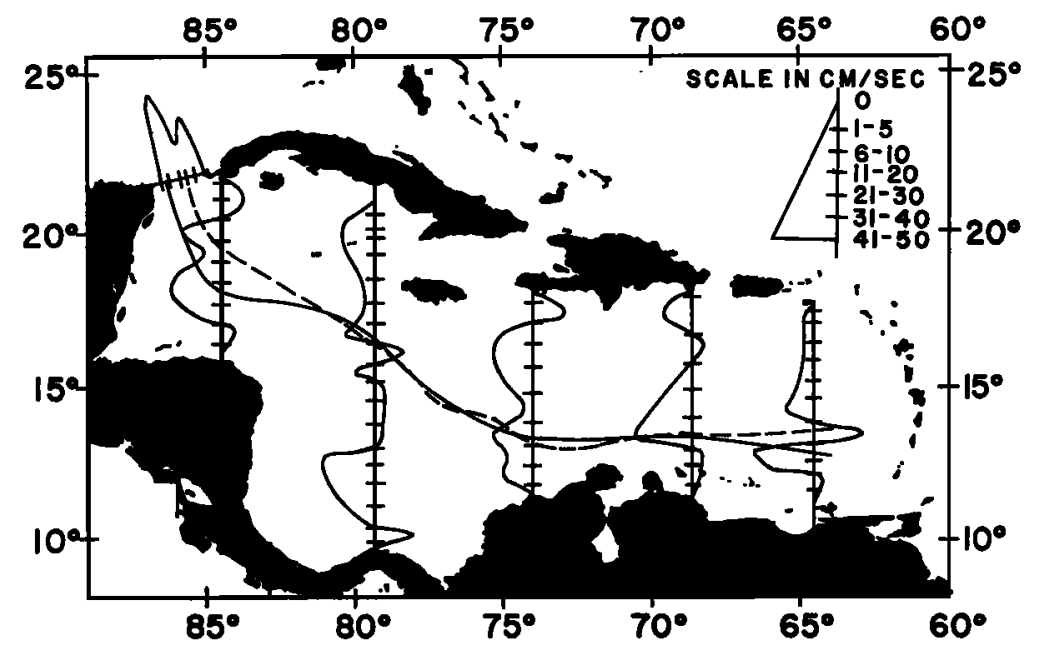

Fig. 6. Geostrophic velocity in core layer of Subtropical Undercurrent 100-200 meters. 


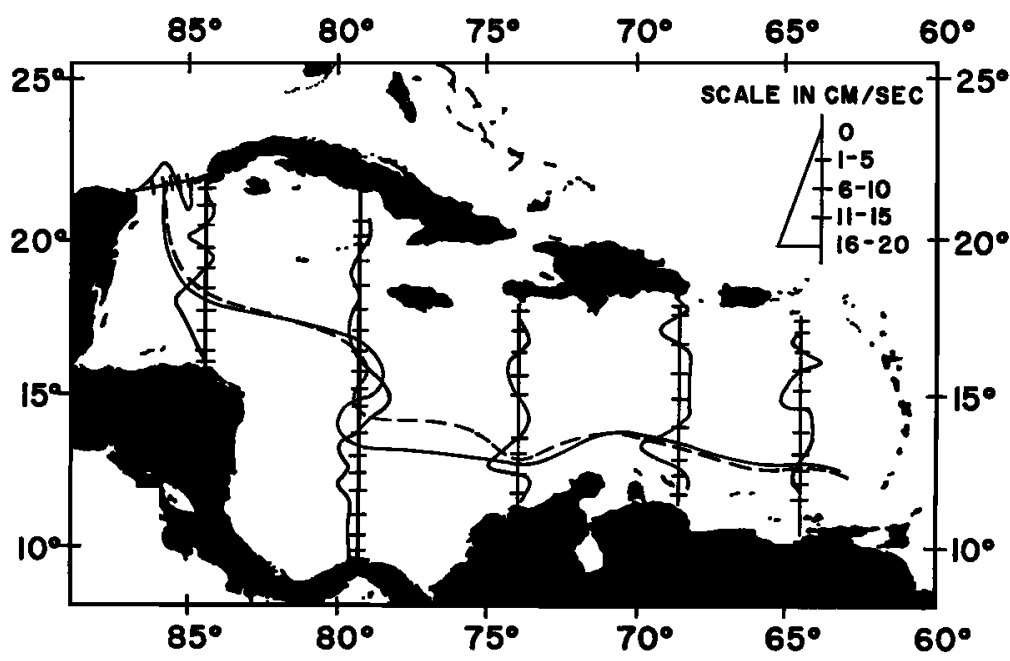

Fig. 7. Geostrophic velocity in core layer of Sub-Antarctic Intermediate Water, 700-850 meters.

derived from the North Atlantic Ocean [Defant, 1961], but the axis of flow is a continuation of the Guiana Current flowing along the South American coast.

The axis of spreading of the Sub-Antarctic Intermediate Water would coincide at all points, since both enter the Caribbean by a southern passage. Figure 7 shows this relationship. The velocities at the axis of flow are approximately $15 \mathrm{~cm} / \mathrm{sec}$. The relationship between the spreading in the upper two core layers and the geostrophic axis of flow confirm the steady-state condition of a well-defined current system in the southern half of the Caribbean Sea.

\section{Volume Transport}

The volume transport calculated from the geostrophic velocities across each of the profiles is listed in Table 2. The average transport is 31 million $\mathrm{m}^{2} / \mathrm{sec}$; however, there is a 10 million$\mathrm{m}^{\mathrm{s}} / \mathrm{sec}$ spread in the values. It is expected that the errors in the total volume transport would be in the vicinity of $30 \%$, since the water flow through the large area below 1200 meters is uncertain, owing to the generally sluggish conditions.

Model [1950] calculated the volume transport through the passageways of the Lesser and Greater Antilles based on current measurements by Pillsbury. Model extrapolated Pillsbury's values from 230 meters to the bottom. He ob- tained a total volume transport of $31 \times 10^{\circ}$ $\mathrm{m}^{8} / \mathrm{sec}$.

Wüst [1924] calculated the volume transport through the Straits of Florida to be $26 \times 10^{\circ}$ $\mathrm{m}^{\mathrm{s}} / \mathrm{sec}$. This transport should be similar to that of the Caribbean Current (assuming little influence of the Gulf of Mexico and the shallow Great Bahama Banks). The transport through the Yucatan Strait of $28 \times 10^{\circ} \mathrm{m} / \mathrm{sec}$ is in good agreement.

The contribution of the flow through the Windward Passage is small and probably less than $5 \times 10^{6} \mathrm{~m}^{8} / \mathrm{sec}$. A certain amount of this transport sinks to the bottom of the Cayman basin. If the necessary upward deep veloci-

TABLE 2. Total Volume Transports through the Caribbean Profiles

\begin{tabular}{|c|c|c|c|}
\hline $\begin{array}{l}\text { Pro- } \\
\text { file }\end{array}$ & $\begin{array}{l}\text { West } \\
\text { Longi- } \\
\text { tude }\end{array}$ & Basin & $\begin{array}{l}\text { Transport, } \\
10^{6} \mathrm{~m}^{2} / \mathrm{sec}\end{array}$ \\
\hline $\mathrm{I}$ & $64^{\circ} 30^{\prime}$ & Eastern Venezuela & 26 \\
\hline II & $68^{\circ} 30^{\prime}$ & Central Venezuela & 33 \\
\hline III & $73^{\circ} 50^{\prime}$ & Colombia & 28 \\
\hline IV & $79^{\circ} 40^{\prime}$ & $\begin{array}{l}\text { Colombia-Cayman- } \\
\text { Yucatan }\end{array}$ & $\mathbf{3 3}$ \\
\hline \multirow{3}{*}{$\begin{array}{l}\text { V } \\
\text { VI }\end{array}$} & $84^{\circ} 30^{\prime}$ & Cayman-Yucatan & 36 \\
\hline & $\cdots$ & Yucatan Straits & 28 \\
\hline & & Average & 31 \\
\hline
\end{tabular}


ties in the Cayman basin to maintain a steadystate condition of the isothermal surfaces are of the order of $10^{-5} \mathrm{~cm} / \mathrm{sec}$ (estimated by Robinson and Stommel [1959] and Stommel and Arons [1960]), an overflow of $10^{4} \mathrm{~m}^{3} / \mathrm{sec}$ is needed. Worthington [1966] believes that this overflow does not occur and that the isotherms are gradually deepening.

\section{Sea Surface Topography}

The topography of the sea surface of the Caribbean Sea is shown in Figure 8. The figure is constructed from the dynamic height anomalies relative to the 1200 -decibar level. Since the geostrophic velocities at this level are small, the topography is approximately absolute. If the surface flow were purely geostrophic, the isobaths would also represent steamlines. Pure geostrophic flow would not be expected because of the added stress of the wind in the Ekman layer.

The total relief of the Caribbean Sea is about one-half of a dynamic meter. The main axis of flow, as found on the surface current charts Wüst [1964] moves 'uphill' by 30 dynamic centimeters before leaving the Caribbean. It accomplishes this vertical movement mainly in two regions: in the region near longitude $79^{\circ} \mathrm{W}$ and between $82^{\circ}$ and $84^{\circ} \mathrm{W}$. There is a minor uphill flow in the southern Venezuela basin. This uphill flow of the Caribbean Current represents added potential energy and must be derived from the wind, since thermohaline alterations in the Caribbean Sea are minor.

The influence of the wind may cause surface flow up or down a slope in the sea surface topography. It is convenient to choose the particular Cartesian coordinate system: the $y$ direction is positive in the direction of the horizontal pressure gradient, the $z$ axis is pointed positively downward and the $x$ axis is parallel to the lines of equal dynamic height. The positive direction of the $x$ axis is taken to yield a left-handed coordinate system. The equation of motion can be written in the following vector form, assuming no accelerations and neglecting the vertical component of the Coriolis force and the terms that include the vertical velocity:

$$
\alpha \nabla \mathbf{P}=f(v \hat{\imath}-u \hat{\jmath})+\alpha \mathbf{F}
$$

where $\hat{\imath}$ and $\hat{j}$ are unit vectors in the $x$ and $y$ directions, respectively, $f$ is the Coriolis param-

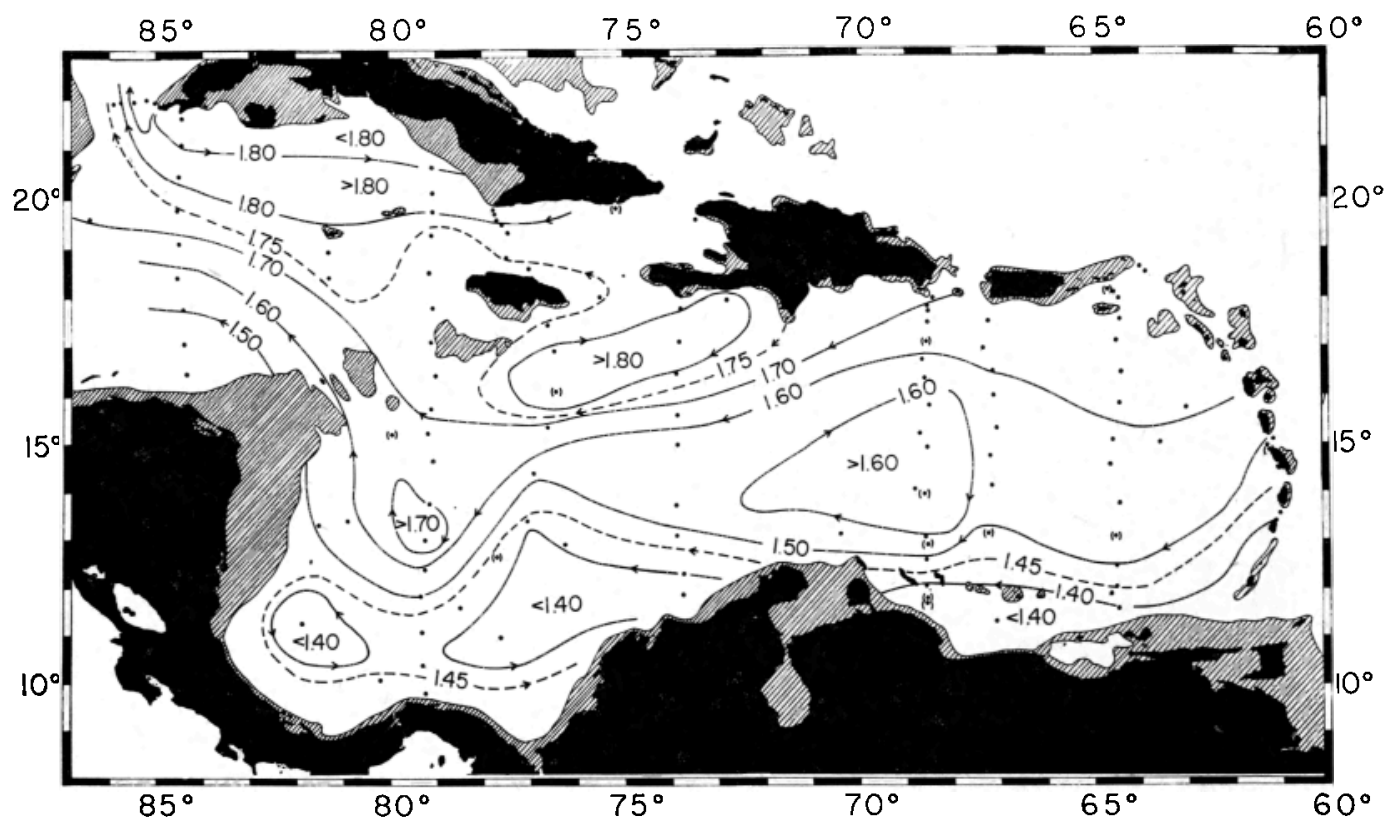

Fig. 8. Dynamic topography of the sea surface relative to the $1200-\mathrm{kb}$ level (values in dynamic meters). 
eter, $(2 \omega \sin \phi)$, and $F$ represents the frictional terms. Equation 1 is then scalar-multiplied by $d x$

$$
0=f v d x+\alpha F_{x} d x
$$

or

$$
v d x=(-\alpha / f)\left(F_{x} d x\right)
$$

The following conditions result:

1. If $F=0$, there is pure geostrophic flow.

2. If $F_{\star} d x$ is negative (as in the case of internal friction or a wind stress opposite to the geostrophic water velocity component), there is a flow down slope.

3. If $F_{s} d x$ is positive (as in the case of wind stress in the same direction as the geostrophic velocity component), the resulting flow has an uphill component.

The last condition is found in the Caribbean Sea. The Northeast Trade Winds cross the Caribbean with their major component in the direction of the geostrophic flow. This results in a westward increase in the energy or dynamic height of the Caribbean Current.

\section{Wind INFLuENCE}

There are two major factors that can create horizontal density differentiation or available potential energy in the oceans. It is this potential energy which can be converted into kinetic energy. The two factors are: the wind and the thermohaline alterations of the sea water. The development of ocean current theory of both types is summarized by Stommel [1957].

The Caribbean area lacks the temperature extremes and the pronounced dominance of evaporation over precipitation for widespread thermohaline convection. The major source of energy for motion in the Caribbean Sea is derived from the wind. "The Northeast Trade Winds which come from the east-northeast and east in the Caribbean Sea are the driving force of the surface currents' [Wüst, 1964 p. 26]. From the geostrophic results, it is observed that the surface baroclinic field extends downward to $1000-1500$ meters. Below this depth the flow is sluggish and is mainly controlled by the inflow from the passageways in the Greater Antilles. It is proposed that the upper baroclinic layer is produced by the wind.

\section{Wind Stress and Surface Currents}

The wind affects the water directly by exerting a stress (force per unit area) on the sea surface. This stress is transmitted downward by frictional coupling. The stress decreases with increasing depth and becomes insignificant below approximately 100-300 meters (the depth of the Ekman layer).

Hidaka [1958] computed the average wind stress over five-degree squares for the world oceans. He used the equations of Munk [1947] and the wind roses published for five-degree squares in the Pilot Charts of the U. S. Navy Oceanographic Office.

$$
\begin{aligned}
& \tau=0.008 \rho W^{2} \quad(W<6.6 \mathrm{~m} / \mathrm{s}) \\
& \tau=0.026 \rho W^{2} \quad(W>6.6 \mathrm{~m} / \mathrm{s})
\end{aligned}
$$

where

$\tau$ is the wind stress at sea surface.

$\rho$ is the air density.

$W$ is the wind speed (in centimeters per seccond).

The coefficients used were proposed by Montgomery [1940], assuming a logarithmic lower wind profile.

The value of the critical wind speed is in doubt, and other authors have proposed values differing from the $6.6-\mathrm{m} / \mathrm{s}$ value from Munk. Experimental work by Deacon et al. [1956] shows a continuous curve of the coefficient of proportionality versus wind speed with an inflection point in the slope at a wind speed of approximately $8 \mathrm{~m} / \mathrm{sec}$. The flat parts of the curve at low and high wind speeds are approximately the same as the values proposed by Montgomery. The equations used by Hidaka relating wind speed to stress can be applied with greatest accuracy to the tropic areas of the ocean, where, because of small sea-air temperature differences, the lower wind profile is logarithmic.

Figure 9 is the fall and spring $5^{\circ}$ average wind stress values (after Hidaka) acting on the sea surface of the Caribbean and neighboring areas. The wind stresses are higher during the spring. The difference between the fall and spring seasons is most pronounced in the southern and eastern parts of the Caribbean. The zonal wind stress for the lower right-hand five- 


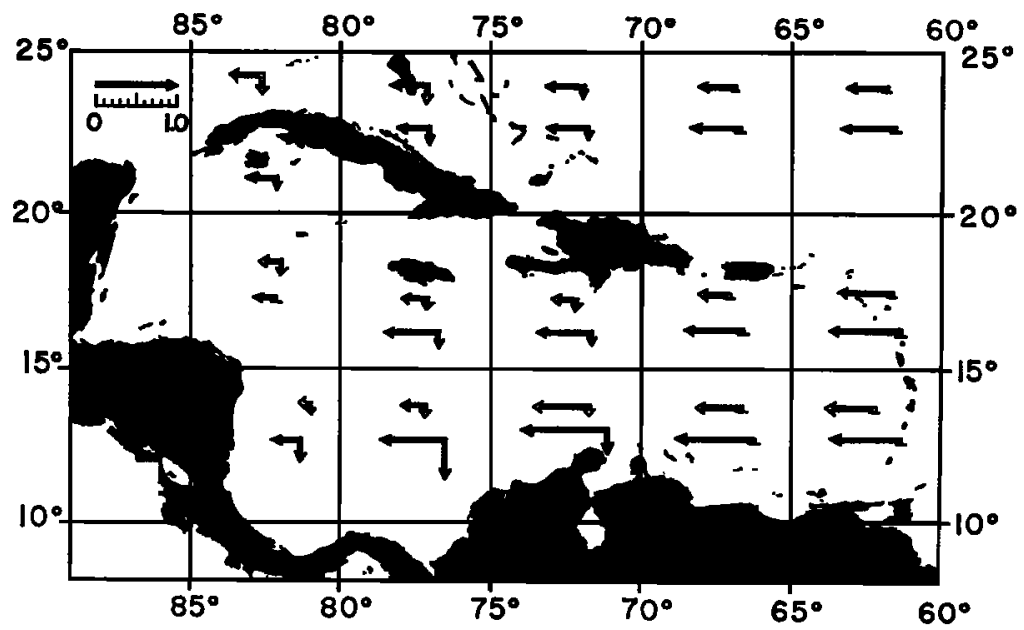

Fig. 9. Wind stress on the Caribbean Sea from Hidaka [1958]. Solid arrows, March, April, May; hollow arrows, September, October, November (values in dynes $/ \mathrm{cm}^{2}$ ).

degree square (center at $12.5^{\circ} \mathrm{N}$ and $57.5^{\circ} \mathrm{W}$ ) is three times higher in the spring than in the fall. The land hinders zonal flow in the western parts of the Caribbean and thus increases the meridional winds. The wind field is generally directed from east to west with a small component of southward flow.

Figure 10 shows the surface current vectors for the months of October and April. Both the wind and current fields are mainly zonal. The wind and the water flow is seasonal with the largest magnitudes in the spring. The velocities along the axis of the Caribbean current are generally between 61 and $82 \mathrm{~cm} / \mathrm{sec}$ during April and between 42 and $61 \mathrm{~cm} / \mathrm{sec}$ for October.
Similarly, the wind stress is, on an average, $40 \%$ higher in the spring. There are localized areas where the thermohaline factor becomes important. They are mostly in the southwestern regions of the Carribbean Sea, where the high rainfall causes a band of light surface, water along the coast and contributes to the formation of a countercurrent.

\section{EFFECT OF WIND ON WaTer STRUCTURE}

In general, the water movement in the western Caribbean Sea and surrounding waters is from the southeast to the northwest. In the Caribbean Sea, the boundaries hinder the formation of a steady-state Ekman drift. Water piles up along

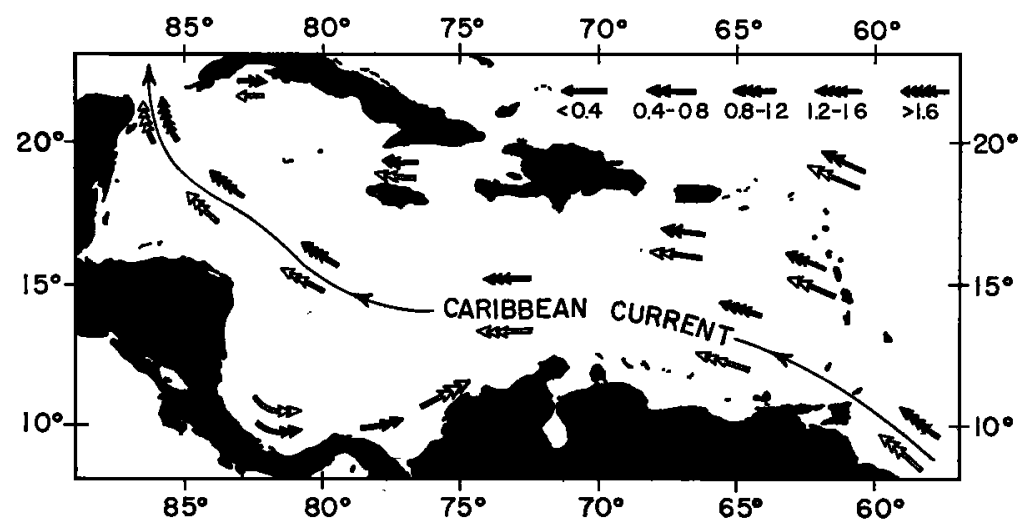

Fig. 10. Surface currents of the Caribbean Sea (modified from Wüst [1964]). Solid arrows, April; hollow arrows, October. (Values in knots.) 
the north boundary, owing to the westward wind stress, and eventually the current becomes parallel to the wind. This is clearly seen in the section of the sea from $65^{\circ}$ to $75^{\circ} \mathrm{W}$, where the sea is narrow and the zonal boundaries are complete, except for the shallow Mona Passage between Puerto Rico and Hispaniola. In the western parts of the Carribbean, the northsouth extent is much greater and the presence of the western boundary with an outlet in the northwest corner permits a surface flow with a northerly component.

Beginning with a barotropic meridional section with complete north and south boundaries with no water movement perpendicular or parallel to it and apply a zonal wind field, the dynamics would go through the following steps: (1) There would be a northward transport in the upper Ekman layer approximately 100 meters thick (for a coefficient of eddy diffusion of $\left.250 \mathrm{~cm}^{2} / \mathrm{sec}\right)$. The northward transport $\left(T_{y}\right)$ would initially be in direct proportion to the $\tau_{v}$ term (where $\tau_{x}$ is the zonal wind stress).

$$
T_{y}=-\tau_{x} / \rho f
$$

(2) The surface waters would begin to pile up on the northern shore and slowly change the barotropic field of mass to a baroclinic field. The wedge of surface water in the north would increase in thickness, and more dense water would accumulate at the surface in the southern part of the section. (3) Equilibrium is then reached when the wind can no longer transport surface water up the north-south sea level slope. When this condition occurs, the baroclinic sea would have a steady-state system of solenoids at right angles to the wind, and the flow is a zonal gradient flow with a superimposed wind current in the Ekman layer. Owing to hydrostatic compensation, the baroclinic field weakens with depth. If the $\tau_{\infty}(y)$ function is not linear, the equilibrium sea surface slope is complicated, being steepest where the zonal wind stress is a maximum.

The vertical motions cause more dense water to reach the surface in the southern end of the section. This intensifies the sea surface slope [Defant, 1961, chapter 17]. Figure 11 is a schematic diagram of the final equilibrium state with the vertical motion that would be present. The core layers are roughly parallel to density surfaces, and so they will slope downward from the south to the north, owing to the 'floating' wedge of light surface water. The isosteres will decrease in slope as the depth increases (as the baroclinic field weakens), and at the deep levels they will be horizontal. The northward slope of the core layers is clearly shown in the profiles of salinity in the Caribbean [Wüst, 1964]. The salinity maximum layer of the Subtropical Underwater slopes from 50 meters depth in the south to 200 meters in the north and occasionally breaks the surface along the South American coast, where upwelling becomes intense. The Sub-Antarctic Intermediate Water also slopes northward but at a lesser angle, usually sloping from 700 meters depth in the south to 800 meters in the north. The divergence produced would be south of the axis of maximum zonal flow. North of the axis, convergence would be present.

The salinity, temperature, and anomaly of specific volume for the upper 1000 meters of the R.V. Crawford section along $74^{\circ} \mathrm{W}$ is shown in Figure 12. The upward slopes of the isopleths toward the southern boundary from the maximum zonal flow display an upwelling feature. The Subtropical Underwater breaks the surface, and the surface temperatures are about $2^{\circ} \mathrm{C}$ lower in the south than in the north. The maximum amount of upwelling occurs about 90 $\mathrm{km}$ from the South American coast, where a line of divergence is formed. The weakening of the thermocline and pycnocline in the south indicates upwelling [Hart and Currie, 1960]. The area of upwelling is contained in the upper 300 meters, and so it is basically a shallow-water feature. The maximum vertical velocities should occur at the bottom of the Ekman layer.

The section of anomaly of specific volume shows the thick wedge of homogeneous surface water in the central and northern parts. It is this water which is carried northward by the Ekman transport until it builds up an opposing sea surface slope and creates a baroclinic sea with its associated geostrophic motion.

The oxygen distribution found by the Crawford profile indicates a surface oxygen concentration of 4.3 to $4.4 \mathrm{ml} / \mathrm{l}$ wich is slightly less than the saturation value of $4.5 \mathrm{ml} / 1$. These values extend to a depth of 75 meters in the north and central regions but only to less than 25 meters in the upwelling area. A wedge of 


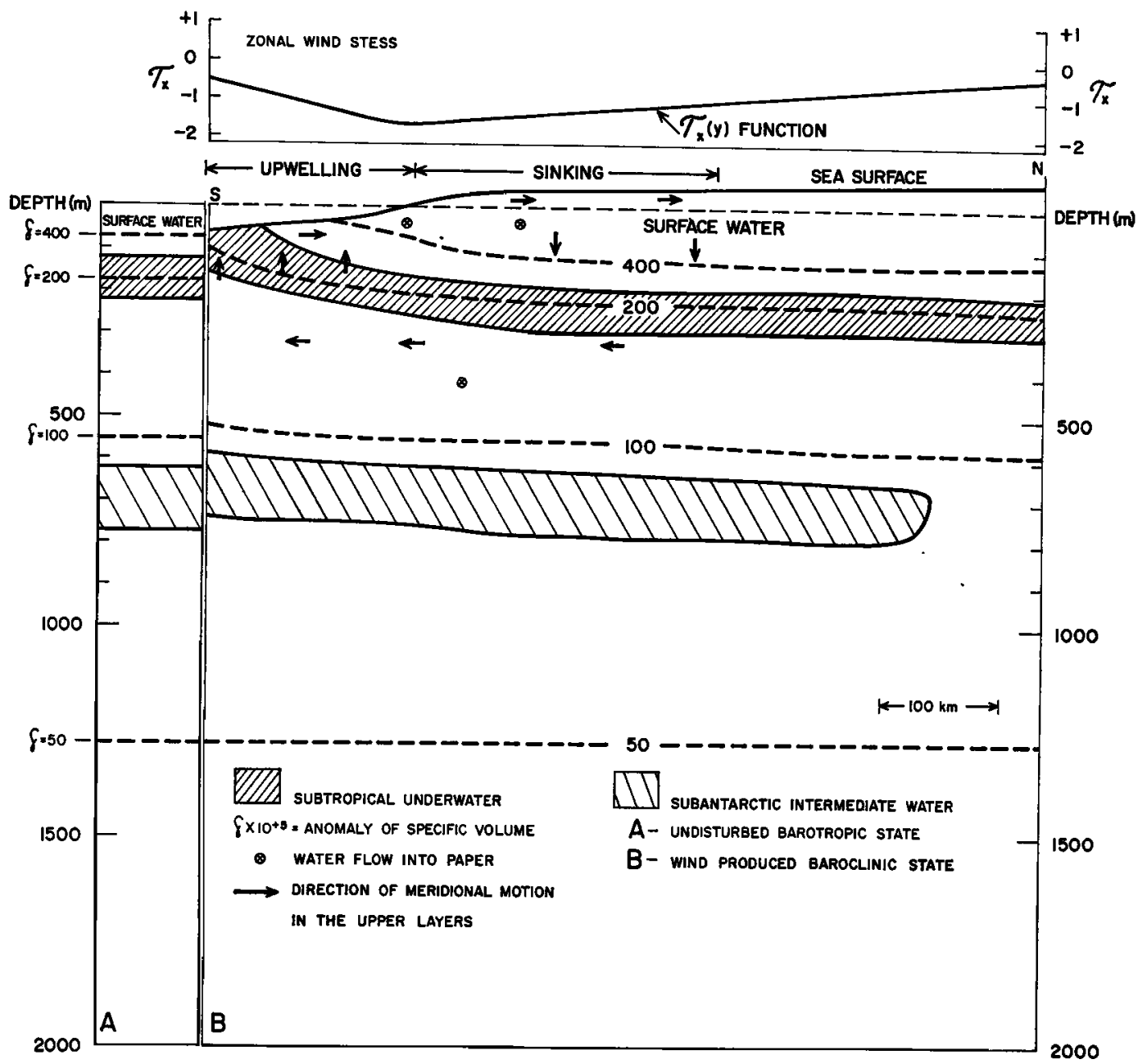

Fig. 11. Schematic of a zonal wind acting on a stratified sea with meridional boundaries. (Sea surface slope exaggerated relative to rest of figure.)

low-oxygen water $(<2.7 \mathrm{ml} / \mathrm{l})$ is found extending from the southern boundary between 300 and 600 meters.

\section{Surface Salinity Rejation to Circulation}

The surface salinity map of the Caribbean Sea may be inspected for information on the full extent of the upwelling area. Besides upwelling, there are other factors that affect surface salinity values; they include the difference between evaporation and precipitation, land runoff, and advection. If upwelling or sinking occurs, the surface salinity distribution would tend to exhibit isolated patches of high or low salinity which may have a coastline as a boundary. This is also true for the evaporation minus precipitation factor but is not true of the horizontal advection. This latter factor would cause a tongue-shaped isohaline distribution. River water discharge would create 'nearshore' low-salinity features.

Therefore, there are two factors that can cause isolated or nearshore high-salinity features: convergence and divergence, and water exchange across the sea-air interface. The annual precipitation is greatest in the west and southwest areas of the Caribbean. It is lowest in the central Venezuela basin region [W üst, 1964]. The summer-fall rainfall is more than twice as high as the winter-spring value. The 
evaporation is higher during the drier season with an average quarter year (winter) value of $46 \mathrm{~cm} /$ quarter and a summer value of $33 \mathrm{~cm} /$ quarter [Colón, 1963; Wüst, 1964].

The winter surface salinity map, Figure 13, shows high salinity values $(>36.5 \%)$ and probably upwelling in two places along the South American coast, between longitude $74^{\circ}-$ $75^{\circ} \mathrm{W}$ and $65^{\circ}-69^{\circ} \mathrm{W}$. There are not sufficient data between these areas to be sure that they are two separated, closed patches of high salinity or one patch that stretches from $65^{\circ} \mathrm{W}$ to $75^{\circ} \mathrm{W}$. The outflow from the Laguna de Maracaibo and the Gulf of Venezuela may be enough to dilute the waters between $70^{\circ}$ and $73^{\circ}$ to salinities less than the $36.5 \%$ value, which is typical of the Subtropical Underwater in the Caribbean. The upwelling extends east of the Caribbean, causing a separation of the Amazon River water from the South American coast. Though summer-autumn surface salinity indicates lower values in the southern Caribbean, owing to increase runoff of the Orinoco and Magdalena rivers [Wüst, 1965], it is believed that upwelling occurs but perhaps to a lesser extent.

The low salinity along Costa Rica and Panama is easily explained by the greater rainfall along this coast associated with orographic lifting. The same is probably true of the area of low salinity along the north coast of Honduras with additional dilution by river discharge. The tongue of low-salinity surface water entering the Caribbean from the southern passages of the Lesser Antilles is a product of the large Amazon River runoff [Wüst, 1964]. The Amazon water remains as a well-defined feature in the central Caribbean during the summer and to a lesser extent during the winter months. This water may well be associated with a line of convergence.

There has been mention of upwelling in the southern sectors of the Caribbean Sea in past literature. The most extensive treatment was given by Richards [1960]. He used a series of Atlantis and Crawford stations extending from the South American coast to $13^{\circ} \mathrm{N}$ and from $62^{\circ}$ to $69^{\circ} \mathrm{W}$ with stations more numerous in the Cariaco trench area. He points out that the colder more saline waters occur along the coast and that the isopleths of various chemical parameters slope upward toward the south. Intense upwelling seems to occur in the eastern end of
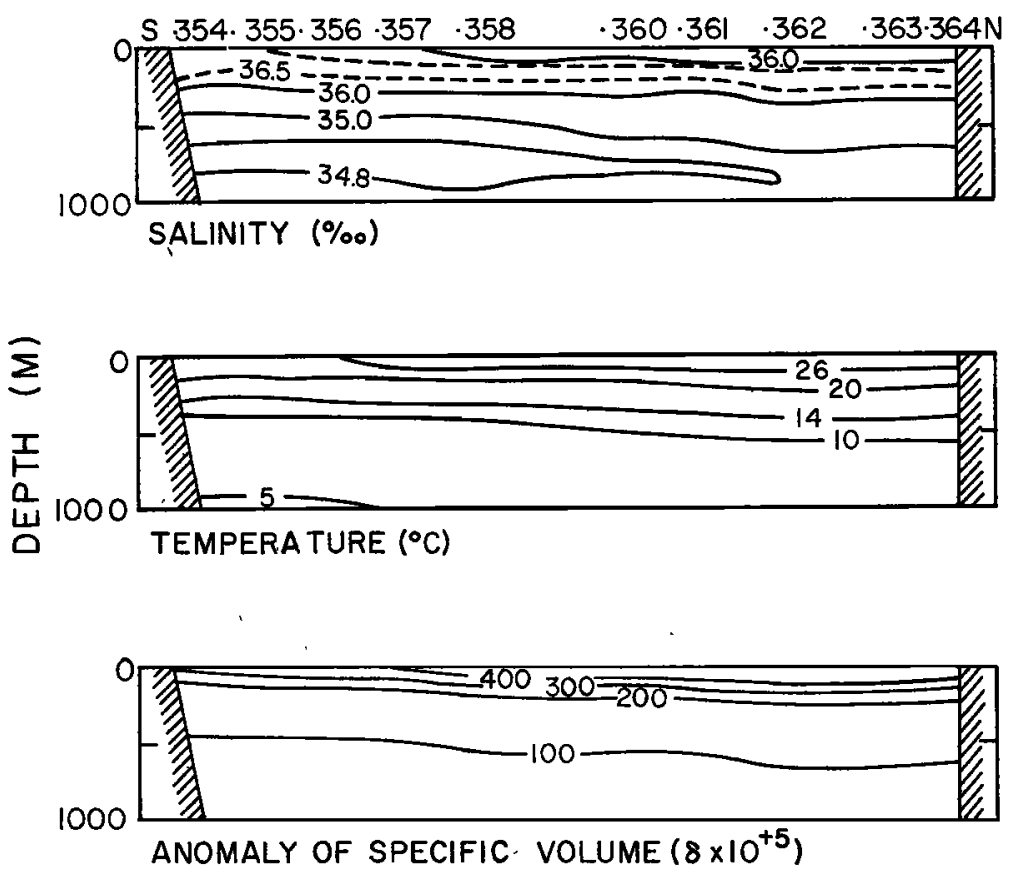

Fig. 12. Salinity, temperature, and specific volume of upper 1000 meters along $73^{\circ} 50^{\prime} \mathrm{W}$ (profile 3). 


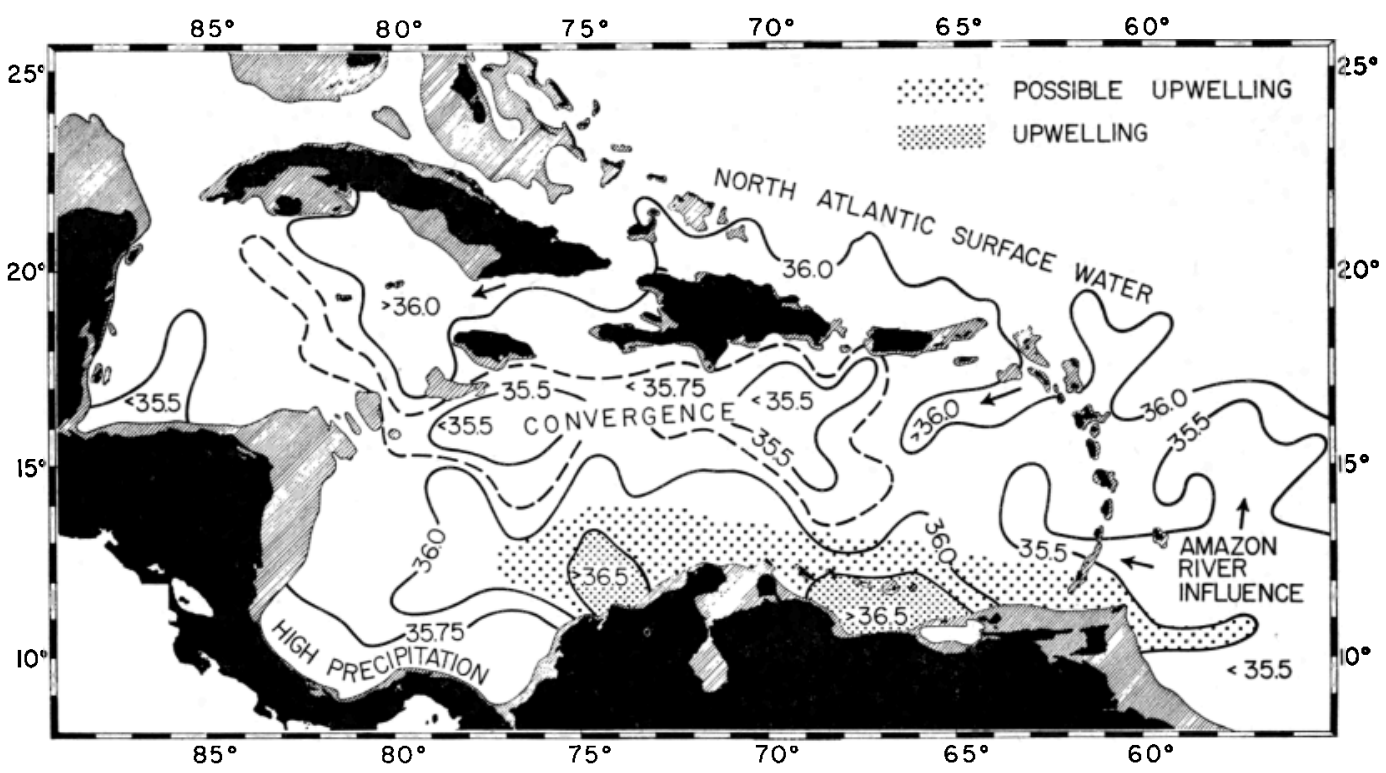

Fig. 13. Schematic representation of factors affecting the winter-spring surface salinity distribution.

the Cariaco trench. Richards discussed the nutrient ion concentration for the Cariaco trench and two north-south profiles along $62.7^{\circ}$ and $64.5^{\circ} \mathrm{W}$ through this trench. He showed that biological productivity is high, which is expected for upwelling areas. From the northward surface flow calculations of Montgomery [1936] and Brooks [1939] Richards determined that upwelling contributes one-half of this transport, the other half coming from the water that flows in from the east. In his calculations, he did not take account of the $\partial T_{x} / \partial x$ term of the continuity equation, where $T_{\infty}$ is the eastwest transport. Therefore, his upwelling value would be too low. It is difficult to convert his value to velocity, since the exact areal extent of the upwelling area is not known nor the variations of its intensity with location and time. He calculated a productivity of $0.14 \mathrm{~cm} \mathrm{c} / \mathrm{m}^{2} /$ day, which is less than the values found by Curl [1960] or $0.32,1.40$, and $0.78 \mathrm{~g} \mathrm{c} / \mathrm{m}^{2} /$ day. His low values can be explained by the oversimplification in the application of the continuity equation, which leads to an underestimate of the amount of upwelling.

Richards noted insignificant upwelling along $68.5^{\circ} \mathrm{W}$. This may indicate that there are two centers of upwelling with an area of weak or no upwelling connecting them.
Fukuoka et al. [1964] mentioned the possibility of upwelling in the southern Caribbean with convergence to the north analogous to the vertical velocity regime, which they discuss as existing in the Cariaco trench.

\section{Calculations of Upwhiling}

The magnitude of the vertical velocities for the Caribbean at $74^{\circ} \mathrm{W}$ can be estimated. The three equations of motion and the continuity equation are combined to relate vertical velocity at the bottom of the Ekman layer with surface wind stress values. The only terms that will be kept in the horizontal equations of motion are the Coriolis term, pressure gradient, and the stress term, which acts on horizontal surfaces. The inertia term and the other frictional terms are ignored. The vertical equation of motion is reduced to the hydrostatic equation.

The equations of motion for the horizontal directions are ( $z$ axis pointed downward, $x$ axis positive toward east, and $y$ axis positive toward north)

$$
\begin{aligned}
& -f v=-\frac{1}{\rho} \frac{\partial p}{\partial x}-\frac{1}{\rho} \frac{\partial \tau_{x}}{\partial z} \\
& +f u=-\frac{1}{\rho} \frac{\partial p}{\partial y}-\frac{1}{\rho} \frac{\partial \tau_{x}}{\partial z}
\end{aligned}
$$


Differentiating equation 5 with respect to $y$ and equation 6 with respect to $x$ and then subtracting the differentiated forms of (5) from (6) results in the following equation:

$$
\begin{aligned}
\frac{\partial \rho}{\partial y} f v+\rho \beta v & +\rho f \frac{\partial v}{\partial y}+\frac{\partial \rho}{\partial y} f u+\rho f \frac{\partial u}{\partial x} \\
& =-\frac{\partial}{\partial x} \frac{\partial \tau_{y}}{\partial z}+\frac{\partial}{\partial y} \frac{\partial \tau_{x}}{\partial z}
\end{aligned}
$$

where $\beta=\partial f / \partial y$. Rearranging and substituting the values of $-f v$ and $f u$ from equations 5 and 6 , respectively, gives

$$
\begin{gathered}
\rho f\left[\frac{\partial u}{\partial x}+\frac{\partial v}{\partial y}\right]=-\frac{1}{\rho} \frac{\partial \rho}{\partial y}\left[\frac{\partial P}{\partial x}+\frac{\partial \tau_{x}}{\partial z}\right] \\
+\frac{1}{\rho} \frac{\partial \rho}{\partial x}\left[\frac{\partial P}{\partial y}+\frac{\partial \tau_{y}}{\partial z}\right] \\
-\frac{\partial}{\partial x} \frac{\partial \tau_{y}}{\partial z}+\frac{\partial}{\partial y} \frac{\partial \tau_{x}}{\partial z}-\rho \beta v
\end{gathered}
$$

Rearranging,

$$
\begin{aligned}
\rho^{2} f\left[\frac{\partial u}{\partial x}\right. & \left.+\frac{\partial v}{\partial y}\right]=\left(\frac{\partial \rho}{\partial x} \frac{\partial P}{\partial y}-\frac{\partial \rho}{\partial y} \frac{\partial P}{\partial x}\right) \\
& -\left(\frac{\partial \rho}{\partial y} \frac{\partial \tau_{x}}{\partial z}-\frac{\partial \rho}{\partial x} \frac{\partial \tau_{y}}{\partial z}\right) \\
& -\rho\left(\frac{\partial}{\partial x} \frac{\partial \tau_{x}}{\partial z}-\frac{\partial}{\partial y} \frac{\partial \tau_{y}}{\partial z}\right)-\rho^{2} \beta v
\end{aligned}
$$

The continuity equation is the following if $\partial \rho / \partial x$ and $\partial \rho / \partial y$ are zero.

$$
-\left(\frac{\partial u}{\partial x}+\frac{\partial v}{\partial y}\right)=\frac{\partial w}{\partial z}
$$

Equation 9 reduces to

$-\rho f \frac{\partial w}{\partial z}=-\frac{\partial}{\partial x} \frac{\partial \tau_{y}}{\partial z}+\frac{\partial}{\partial y} \frac{\partial \tau_{x}}{\partial z}-\rho \beta v$

Equation 11 would be valid in a homogeneous water body, but, if stratification is present, equation 9 must be used. The first term on the right-hand side of equation 9 is approximately zero. This can be demonstrated as follows. From the hydrostatic equation

$$
P=g \int_{z 0}^{z} \rho d z=g \rho(m)\left[Z-Z_{0}\right]
$$

where $\boldsymbol{\rho}(m)$ is the mean density in the interval of depth $Z-Z_{0}, Z_{0}$ is the sea surface, and $Z$ is a distance below the sea surface. (Therefore, $Z-Z_{0}$ is not dependent on $x$ or $y$.) The first term to the right of the equal sign of equation 9 becomes

$$
g\left(Z-Z_{0}\right)\left[\frac{\partial \rho}{\partial x} \frac{\partial \rho(m)}{\partial y}-\frac{\partial \rho}{\partial y} \frac{\partial \rho(m)}{\partial x}\right]
$$

In a region with parallel density surfaces over the interval $Z-Z_{0}$ equation 13 is equal to zero since $\partial \rho / \partial x=\partial \rho(m) / \partial x$ and $\partial \rho / \partial y=\partial \rho(m) / \partial y$. If the density does not vary over the $Z-Z_{0}$ depth interval, as in the upper few meters, the term is zero. In the following calculations, the integration is performed to the depth at which $\tau_{s}$ and $\tau_{v}$ are zero, Ekman's frictional depth. Equation 13 does not become important until a strong pycnocline is reached; thus, it will be dropped in these calculations, reducing equation 9 to

$$
\begin{gathered}
-\rho^{2} f \frac{\partial w}{\partial z}=-\left(\frac{\partial \rho}{\partial y} \frac{\partial \tau_{x}}{\partial z}-\frac{\partial \rho}{\partial x} \frac{\partial \tau_{y}}{\partial z}\right) \\
-\rho\left(\frac{\partial}{\partial x} \frac{\partial \tau_{y}}{\partial z}-\frac{\partial}{\partial y} \frac{\partial \tau_{x}}{\partial z}\right)-\rho^{2} \beta v
\end{gathered}
$$

Equation 14 is integrated from the sea surface, $Z=0$, to the depth of the Ekman layer, $Z=E$. The vertical velocity at the sea surface is zero, and the vertical velocity at the bottom of the Ekman layer is $w(E)$. Since the $z$ axis is pointed downward, positive $w$ values indicate sinking whereas upwelling has negative $w$ values.

$$
\begin{aligned}
\rho^{2} f w(E)= & \int_{0}^{E}\left(\frac{\partial \rho}{\partial y} \frac{\partial \tau_{x}}{\partial z}-\frac{\partial \rho}{\partial x} \frac{\partial \tau_{y}}{\partial z}\right) d z \\
& +\rho \int_{0}^{E}\left(\frac{\partial}{\partial x} \frac{\partial \tau_{y}}{\partial z}-\frac{\partial}{\partial y} \frac{\partial \tau_{x}}{\partial z}\right) \\
& +\rho^{2} \beta \int_{0}^{E} v d z
\end{aligned}
$$

The following assumptions are made to reduce the above equation:

1. $\rho^{2} \beta \int_{0}^{\pi} v d z=0$.

2. Terms involving $\tau$, are equal to 0 (later this term is included in the treatment).

3. The 50-meter value of $\partial \rho / \partial y$ is representative of the $\partial \rho / \partial y$ value in the depth interval from the sea surface to depth $E$.

4. The $\partial \tau_{s} / \partial z$ term is linear from the sea surface to the Ekman frictional depth and is 
nearly zero at this depth, $\tau_{m}=\tau_{x}$ at $Z=0$ and $\tau_{s .}=0$ at $Z=E$.

Equation 15 reduces to

$$
\begin{gathered}
\left.\rho^{2} f w(E)=\frac{\partial \rho}{\partial y}\right)_{50} \int_{0}^{E} \frac{\partial \tau_{x}}{\partial z} d z \\
+\rho \int_{0}^{E}\left(-\frac{\partial}{\partial y} \frac{\partial \tau_{x}}{\partial z}\right) d z \\
\left.\left.\frac{\partial \rho}{\partial y}\right)_{50} \int_{0}^{E I} \frac{\partial \tau}{\partial z} x d z=-\frac{\partial \rho}{\partial y}\right)_{50} \tau_{x}
\end{gathered}
$$

An assumption must be made as to the value of $\partial / \partial y \partial \tau_{x} / \partial z$. In the $10^{\circ}$ latitude from $10^{\circ}$ to $20^{\circ} \mathrm{N}$, the average wind stress (east-wind component) over the southern half is -1.51 dynes $/ \mathrm{cm}^{2}$, and for the northern half, the average value is -0.73 dynes/ $\mathrm{cm}^{2}$ (from Hidaka's [1958] tables). It is possible to construct a $\tau_{x}(y)$ function which would give an average stress value that agrees with Hidaka's value and would yield, to a first approximation, zonal flow similar to what is observed. Using this $\tau_{x}(y)$ function, the above assumptions (equations 16 and 17) and the data from R.V. Crawford stations 355 and 356 (to find the $\partial \rho / \partial y$ value) the upwelling at the base of the Ekman layer in the southern end of profile 3 is found to be $6 \times 10^{-4} \mathrm{~cm} / \mathrm{sec}$. If meridional winds are not neglected, the upwelling is reduced to $4 \times 10^{-4}$ $\mathrm{cm} / \mathrm{sec}$.

Acknowledgments. I wish to thank Dr. Georg Wüst under whose advice and guidance this work was prepared. I also thank Drs. Nafe and Ichiye for their helpful comments. The financial support of the United States Atomic Energy Commission under Contract AT(30-1)2663 is gratefully acknowledged.

\section{REFERENCES}

Brooks, E. M., Transport and convergence of the North Atlantic drift current computed from the average January pressure distribution, $J$. Marine Res., 2(2), 163-167, 1939.

Cochrane, J. D., Yucatan Current, Texas A\&M Ann. Rept. Project 286 Ref. 69-18A, 1964.

Colón, F. A., Seasonal variations in heat flux from the sea surface to the atmosphere over the Caribbean Sea, J. Geophys. Res., 68(5), 14211430, 1963.

Curl, H., Jr., Primary production measurements in the north coastal waters of South America, Deep-Sea Res., 7, 183-189, 1960.
Deacon, E. L., P. A. Sheppard, and E. K. Webb, Wind profiles over the sea and the drag at the sea surface, Australian J. Phys., 9, 511-541, 1956.

Defant, A., Die absolute Topographie des physikalischen Meeresniveaus und der Druckflächen, sowie die Wasserbewegungen im Atlantischen Ozean, Meteor Exp. 1925-27, vol. 6, part 2(5), 1941.

Defant, A., Physical Oceanography, vol. 1, 729 pp., Pergamon Press, New York, 1961.

Dietrich, G., Das Amerikanische Mittelmeer, $Z$. Ges. Erd., 1939.

Fomin, L. M., The Dynamic Method in Oceanography, Elsevier Publishing Co., 1964.

Fukuoka, J., A. Ballester, and F. Cervigon, An analysis of hydrographical conditions in the Caribbean Sea, III-especially about upwelling and sinking, Studies on Oceanography, Hidaka commemoration, 145-149, Univ. of Washington Press, Seattle, 1964.

Gordon, A. L., Quantitative study of the dynamics of the Caribbean Sea, Columbia University doctorate dissertation, New York, $237 \mathrm{pp}$., 1965.

Hart, T. B., and R. I. Currie, The Benguela Current, Discovery Rept. 81, 123-298, 1960.

Hidaka, K., Computation of the wind stresses over the oceans, Rec. Oceanog. Works Japan, 4, 77-123, 1958.

Model, F., Pillsbury's Strommessungen und der Wasserhaushalt des Amerikanischen Mittelmeeres, Deut. Hydrol. Z., $\$(1,2), 1950$.

Montgomery, R. B., Transport of surface water due to the wind system over the North Atlantic, Paper Phys. Oceanogr. Meteorol., 4(3), 23-30, 1936.

Montgomery, R. B., Observations of vertical humidity distribution above the ocean surface and their relation to evaporation, Paper Phys. Oceanogr. Meteorol., 7, 30 pp., 1940.

Munk, W., A critical wind speed for air-sea boundary processes, J. Marine Res., 6, 203-218, 1947.

Parr, A. E., A contribution to the hydrography of the Caribbean and Cayman Seas, Bull. Bingham Oceanogr., coll. 5, art. 4, 1-110, 1937.

Pillsbury, J. E., Gulf Stream explorations, Observations of currents, Appendix 8, U. S. Coast and Geodetic Survey, 1887.

Reid, R. O., Influence of some errors in the equation of state or in observations on geotrophic currents, Physical and Chemical Properties of Sea Water. Natl. Acad. Science-Natl. Res. Council, Publ. 600, 1959.

Richards, F., Some chemical and hydrographic observations along the north coast of South America, Deep-Sea Res., 7, 163-182, 1960.

Robinson, A., and H. Stommel, The oceanic thermocline and the associated thermohaline circulation, Tellus, 11, 1959.

Sandström, J. W., and B. Helland-Hansen, Utber die Berechnung von Meeresströmungen, Rept. Norwegian Fisheries Invest., 2(4), 43 pp., 1903.

Seiwell, H. R., The effects of short-period variations in dynamic oceanography, Paper Phys. Oceanogr. Meteorol., 7(3), 1939. 
Stommel, $H$., A survey of ocean current theory, Deep-Sea Res., 4, 149-184, 1957.

Stommel, H., and A. B. Arons, On the abyssal circulation of the world ocean, 1 and 2, DeepSea Res., 6, 1960 ,

Sturges, Wilton, Water characteristics of the Caribbean Sea, J. Marine Res., 28(2), 147-162, 1965.

Worthington, L. V., A new theory of Caribbean bottom water formation, Deep-Sea Res., 3, 6287, 1955.

Wortlington, L. V., Recent oceanographic measurements in the Caribbean Sea, Deep-Sea Res., $13,731-739,1966$.

Wüst, G., Florida und Antillenstrom eine hydro- dynamische Untersuchung, Verhandl. Inst. Meer, Berlin, N.F.A., vol. 12, 1924.

Wüst, G., On the stratification and circulation in the cold water sphere of the Antillean-Caribbean basins, Deep-Sea Res., 10, 165-187, 1963.

Wüst, G., Stratification and Circulation in the Antillean-Caribbean Basins, Part 1, Spreading and mixing of the water types with an oceanographic atlas, 201 pp., Columbia University Press, New York, 1964.

Wüst, G., Wasser-und Wärmehaushalt und Zirkulation in der Warmwassersphäre des Karibischen Meeres, Kieler Meeresforsch., 21(1), 1965.

(Received February 17, 1967; revised August 2, 1967.) 